2021:6(1):21-26

http://ojs.uho.ac.id/index.php/JIA

doi: http://dx.doi.org/10.37149/JIA.v6i1.16284

\title{
PERAN TENAGA KERJA DALAM PENINGKATAN PRODUKSI BAWANG MERAH DI KEBUN PRAKTEK FAKULTAS PERTANIAN UNIVERSITAS NUSA NIPA
}

\author{
Elias Raymond Padeng ${ }^{\left.1^{*}\right)}$, Sarlina Noni ${ }^{1)}$ \\ ${ }^{1}$ Program Studi Agribisnis, Universitas Nusa Nipa \\ *Corresponding author: padenggg17@gmail.com
}

To cite this article:

Padeng, E., \& Noni, S. (2021). Peran Tenaga Kerja dalam Peningkatan Produksi Bawang Merah di Kebun Praktek Fakultas Pertanian Universitas Nusa Nipa. JIA (Jurnal IImiah Agribisnis) : Jurnal Agribisnis dan IImu Sosial Ekonomi Pertanian, 6(1), 21 - 26. doi:http://dx.doi.org/10.37149/jia.v6i1.16284

Received: January 28, 2021; Accepted: February 27, 2021; Published: February 28, 2021

\section{ABSTRACT}

Labor can increase shallot's production because Labor is a tool to carry out the production process. The aim to analyze the role of Labor in increasing Shallot Production. Research adapted descriptive research, the data carried out by researchers from library research and field research. The data sources from respondents, and also from the research implementation 01 October-01 November 2021. Furthermore, the data collection methods used were observation and questionnaires by Descriptive Analysis Method and Spearman Rank Correlation Test Analysis. The results found that the role of Labor in increasing the productivity of shallot plants in the Unipa garden was classified as very important based on two indicators consisting of Labor and increased production, which had been researched on 30 respondents and the results of the correlation test that had been conducted, it can be seen a positive and significant value relationship between Role of Labor and the Increase of Red Onion Production in the Gardens of the Faculty of Agriculture, Nusa Nipa University.

Keywords: labor; onion production; production; red onion

\section{PENDAHULUAN}

Faktor utama dalam produksi adalah keberadaan tenaga kerja, karena memiliki fungsi utama dalam diperhitungkan dalam kegiatan pertanian. Ketersediaan tenaga kerja yang mapan akan memberikan kualitas yang baik dalam proses produksi suatu produk pertanian, oleh karena itu penampilan kerja menjadi suatu hal yang perlu untuk dijaga (Soekartawi, 2003). Menurut undangundang ketenagakerjaan No. 13 tahun 2003, tenaga kerja diartikan sebagai setiap orang yang melakukan produksi barang untuk memenuhi kebutuhan diri sendiri atau masyarakat. Karena tenaga kerja merupakan alat untuk melakukan proses produksi, tenaga kerja memiliki peran dalam suatu pendapatan yang sangat penting, dan jumlah tenaga kerja harus diperhatikan dalam proses produksi tersebut, tidak hanya ketersediaannya, tetapi juga kualitasnya dan jenisnya. Produksi suatu produk oertania perlu dilengkapi dengan ketersedian tenaga kerja yang kompeten serta seberapa banyak jumlah yang dibutuhkan akan diaplikasikan sesai dengan kebutuhan pertanian disesuaikan dengan level tertentu sesuai kepenuhan agar mencapai kondisi terbaik (Guo dkk., 2015).

Salah satu komoditas holtikultura dalam produksi sektor pertanian di Indonesia yang memiliki nilai tambah ekonomi dan penyerapan tenaga kerja potensial adalah tanaman bawang merah (Allium ascolonicum L), dimana termasuk komoditas sayuran yang dalam peningkatan produksinya lebih mengutamakan perbaikan teknologi budidaya. Dalam pengelolahan budidaya bawang merah menggunakan ketersediaan pekerja dinyatakan sebagai curahan tenaga kerja. Curahan tenaga kerja didefinisakan sebagai tingkatan pekerja yang memiliki nilai efektif. Konversi waktu seorang pria dapat dikonversikan hari kerja pria (HKP) sesuai dengan 8 jam kerja efektif perhari (Rahim dan Diah, 2008).

Proses budidaya bawang merah yang sangat optimal dalam pertanian dapat ditersukan dengan proses pasca panen, pada tahap ini kan memberikan nilai kepada bidang pekerjaan yang baru. Proses pasca panen memiliki nilai yang sangat tinggi dalam upaya keberhasilan suatu prodak, oleh karena itu dibutuhkan tenaga kerja yang kompeten terutama dibidang teknologi sehingga dapat diterapkan dalam proses agribisnis. Produksi bawang merah yang selalu berubah dari waktu kewaktu 
menyebabkan perubahan nilai pasar yang sangat fluktuatif menyebabkan beberpa petani cenderung untuk sulit menentukan harga normal guna mendapatkan keuntungan. Mempromosikan investasi dalam infrastruktur pertanian dan layanan penyuluhan bersama mengadopsi langkah-langkah yang bertujuan dalam meningkatkan nilai oembelian dalam rumah tangga, terutama di pedesaan daerah, tampaknya menjadi pendorong utama dalam peningkatan ketersediaan akses pangan (Pawlak dan Kołodziejczak, 2020).

Kabupaten Sikka terletak di Provinsi Nusa Tenggara Timur Indonesia, termasuk dalam wilayah dengan mata pencaharian utama adalah sebagai petani. Salah satu usaha pertanian di Kabupaten Sikka tahun 2019 melaporkan bahwa pertanian bawang merah, dengan luas lahan sebesar $26 \mathrm{Ha}$. Kebun Fakultas Pertanian Universitas Maumere Nusa Nipa ini merupakan tempat magang bagi mahasiswa Fakultas Pertanian yang berlokasikan di Jl. Litbang Kelurahan Kota Uneng. Berbagai tanaman hortikultura dibudidayakan secara organik dan dijual ke konsumen. Secara teknis budidaya bawang merah masih tergolong semi tradisional, dimana lahan diolah dengan menggunakan mesin pertanian (traktor), pembuatan bedengan, penaburan bibit, pemeliharaan, pemupukan, panen hingga pemasaran yang membutuhkan tenaga kerja.

Penelitian Palacios-Lopez dkk., (2017) menjelaskan peran tenaga kerja wanita cenderung lebih tinggi di rumah tangga di mana wanita memiliki bagian tanah yang lebih besar dan saat mereka lebih berpendidikan. Pengendalian gender dan profil pengetahuan responden tidak secara berarti mengubah prediksi pangsa tenaga kerja perempuan. Penelitian ini bertujuan menganalisis peran tenaga kerja dalam pengolahan dan peningkatan produktivitas bawang merah di Kebun Fakultas Pertanian Universitas Nusa Nipa.

\section{MATERI DAN METODE}

Penelitian dilaksanakan di Kebun Fakultas Pertanian Universitas Nusa Nipa Indonesia, Jalan Litbang, Kelurahan Kota UnengKabupaten Sikka. Penelitian berlangsung dari 1 oktober- 1 November 2020. Jenis penelitian berupa analisis deskripsi yaitu menggambarkan sistem pertanian di Kebun Unipa dengan mengkaji fenomenna peran tenaga kerja, dengan fenomena peningakatan produksi bawang merah. Sistem pengukuran yang digunakan merujuk pada skala likert (Sugiyono, 2012).

Adapun sumber data penlitian:

a. Data Primer didapatkan dari hasil observasi langsung pada objek penelitian ini dalam mengisi kusioner oleh para tenaga kerja bawang merah dan konsumen yang membeli hasil produksi di Kebun Praktek Fakultas Pertanian Universitas Nusa Nipa Indonesia.

b. Data Sekunder didapatkan dari studi literature dan data dari dinas pertanian.

Analisis Data untuk mengetahui hubungan tingkat pengetahuan dengan motivasi petani dalam berusaha tani bawang merah adaptasi Uji Korelasi Rank Spearman (Sugiyono, 2013):

Keterangan :

$$
r s(r h o)=1-\frac{6 \sum \quad d^{2}}{n\left(n^{2}-1\right)}
$$

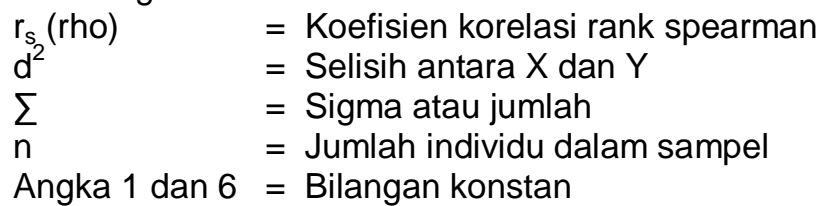

Proses distribusi data berdasarkan nilai yang diperoleh melalui kelas interval sebagai berikut.

Tabel 1. Kelas interval pencapaian

\begin{tabular}{ccc}
\hline No & Pencapaian & Kategori \\
\hline 1 & $75 \%-100 \%$ & Sangat berperan. \\
2 & $50 \%-74,99 \%$ & Berperan \\
3 & $25 \%-49,99 \%$ & Kurang berperan \\
4 & $0 \%-24,99 \%$ & Tidak berperan \\
\hline
\end{tabular}

Uji Koefisien Korelasi Rank Spearman hubungan antara peran tenaga kerja dan peningkatan produksi bawang merah adalah:

a. Jika nilai sig. $<0,05$ maka dapat disimpulkan bahwa terdapat korelasi signifikan antara peran tenaga kerja dan peningkatan produksi bawang merah. 
b. Jika nilai sig. > 0,05 maka dapat disimpulkan bahwa tidak terdapat korelasi signifikan antara antara peran tenaga kerja dan peningkatan produksi bawang merah.

Kriteria tingkat hubungan (koefisien korelasi) antar variabel berkisar antara $\pm 0,00- \pm 1,00$ tanda (+) adalah positif dan tanda (-) adalah negatif. Adapun kriteria penafsirannya diadaptasi dari Hauke dan Kossowski, (2011)\ adalah:

a. 0,00 sampai 0,20 : tidak ada korelasi.

b. 0,21 sampai $0,40:$ korelasi rendah.

c. 0,41 sampai $0,60:$ korelasi sedang.

d. 0,61 sampai $0,80:$ korelasi tinggi.

e. 0,81 sampai 1,00 : korelasi sempurna.

\section{HASIL DAN PEMBAHASAN}

\section{Karakteristik Responden Penelitian}

Responden penelitian adalah tenaga kerja di Kebun Fakultas Pertanian Unipa. Karakteristik responden meliputi usia, pendidikan, dan tanggungan keluarga. Faktor umur sangat mempengaruhi fisik bekerja dan cara berpikir seseorang.

Tabel 2. Responden di kebun Fakultas Pertanian Universitas Nusa Nipa Indonesia

\begin{tabular}{cccc}
\hline No. & Deskripsi & Jumlah & Presentase (\%) \\
\hline 1 & Umur (tahun) & & \\
\hline \multicolumn{2}{c}{$15-55$} & 30 & 100,00 \\
\hline 2 & Pendidikan & - & - \\
\hline Tidak Sekolah & - & 0 \\
& SD & - & 0 \\
& SMP & 1 & 3,3 \\
& SMA & 8 & 26,66 \\
& Diploma & 4 & 13,33 \\
& Sarjana & 17 & 56,66 \\
\hline 3 & Jumlah Tanggungan Keluarga (Jiwa) & & 66,66 \\
& 1-3 & 20 & 33,33 \\
& $4-6$ & 10 & 0 \\
\hline
\end{tabular}

Jumlah responden yang berusia produktif yaitu sebanyak 30 orang (100\%) (Tabel 2). Maka dapat di jelaskan bahwa ketersediaan tenaga kerja untuk sektor pertanian masih cukup tinggi. Namun faktor umur seseorang tidak membatasi para petani untuk melakukan kegiatan bertani. Pendidikan dapat mempengaruhi produktifitas dimana usahatani akan meningkat bila mutu tenaga kerja dapat ditingkatkan melalui pendidikan. Tingkat pendidikan didominasi oleh sarjana $(56,66 \%)$ disusul SMA $(26,66 \%)$ selanjutnya Diploma (13,33\%) dan SMP (3,3\%).

Besar kecilnya tanggungan keluarga dalam setiap rumah tangga tenaga kerja responden berkaitan dengan peningkatan produksi bawang merah. Jumlah tanggungan lebih banyak melebihi 3 orang $(66,66 \%)$ sehingga banyaknya anggota keluarga juga akan mempengaruhi perekonomian keluarga responden. Demografi berupa usia, tingkat pendidikan dan Jumlah didalam keluarga memiliki korelasi terhadap keterampilan, karakteristik untuk mengaplikasikan tingkatan produksi serta pertimbangan dalam yang menunjang produksi bawang merah (Devi dan Hartono, 2016; Persaud Ajax dan Schillo Sandra R., 2017; Rijal dkk., 2016; Seegebarth Barbara dkk., 2016).

\section{Peranan Tenaga Kerja Dalam Meningkatkan Produktivitas Bawang Merah Di Kebun Praktek Fakultas Pertanian Universitas Nusa Nipa Indonesia}

\section{Indokator Tenaga Kerja}

Tenaga kerja memberikan peran penting dalam peningkatan produktivitas bawang merah di kebun Fakultas Pertanian Universitas Nusa Nipa Indonesia. Tenaga kerja diarahkan pada kemampuan untuk meningkatakna fungsi pekerjaan. Hasil pengamatan dan interview langsung diketahui bahwa peran tenaga kerja terhadap kuantitas tenaga kerja, memberikan kontribusi terhadap produktivitas tanaman bawang merah pada setiap musim tanam. 
Tabel 3. Indikator tenaga kerja dan indikator peningkatan produksi bawang merah

\begin{tabular}{|c|c|c|c|c|}
\hline No & Indikator & Skor & $\%$ & Kategori \\
\hline \multirow[t]{4}{*}{1} & Tenaga Kerja & & & \\
\hline & Kuantitas Tenaga Kerja & 102.5 & 68.165 & Berperan \\
\hline & Kualitas Tenaga Kerja & 94,25 & 62,83 & Berperan \\
\hline & Ketepatan Waktu & 101,75 & 67,83 & Berperan \\
\hline \multirow[t]{4}{*}{2} & Peningkatan Produksi Bawang Merah & & & \\
\hline & Lahan & 130,66 & 87,11 & Sangat Berperan \\
\hline & Modal & 133,33 & 88,88 & Sangat Berperan \\
\hline & Tenaga Kerja & 134,33 & 89,55 & Sangat Berperan \\
\hline
\end{tabular}

Hasil penelitian mengenai peranan tenaga kerja dalam peningkatan produktivias bawang merah dapat diketahui dari setiap item pernyataan yang diajukan secara deskriptif. Peranan tenaga kerja dalam peningkatan produksi bawang merah pada bagian kuantitas tenaga kerja berada dalam kategori berperan, dengan interval sebesar 68,165\%. Sedangkan Peran tenaga kerja dalam peningkatan produktivitas bawang merah pada bagian kualitas tenaga kerja yang dalam kategori berperan, dengan nilai $62,83 \%$. Peranan tenaga kerja dalam peningkatan produksi bawang merah pada bagian ketepatan waktu berada dalam kategori Berperan, dengan rentang interval sebesar $67,83 \%$ (Tabel 3). Pemahaman akan teknologi dapat dilihat dari penggunaan sarana produksi, pemupukana dan panen. Penanganan pasca panen bagi semua hasil produksi tanaman bawang merah yang berada di kebun Praktek Fakultas Pertanian Universitas Nusa Nipa Indonesia dilakukan dengan baik sesuai SOP yang berlaku di kebun praktek, sampai pada tahap pemasaran.

\section{Indikator Peningkatan Produksi Bawang Merah}

Hasil pengamatan lapangan dan wawancara secara langsung diketahui peran tenaga kerja dalam Lahan, memberikan kontribusi terhadap produktivitas tanaman bawang merah pada setiap musim tanam. Peranan tenaga kerja dalam peningkatan produktivitas bawang merah pada bagian Lahan, dalam kategori sangat berperan, dengan rentang interval sebesar $87,11 \%$, Sedangkan pada bagian Modal, berada dalam kategori sangat berperan, $88,88 \%$, peranan tenaga kerja dalam peningkatan produktivitas bawang merah pada bagian tenaga kerja, berada dalam kategori sangat berperan, dengan rentang interval sebesar $89,55 \%$ (Tabel 3).

\section{a. Hubungan Antara Tenaga Kerja Dalam Peningkatan Produktivitas Bawang Merah Di Kebun Fakultas Pertanian Universitas Nusa Nipa Indonesia}

Hubungan tenaga kerja dengan peningkatan produksi bawang Merah dianalisis menggunakan Uji Korelasi Rank Sperman.

Tabel 4. Analisis korelasi rank spearman produktivitas bawang merah.

\begin{tabular}{|c|c|c|c|c|}
\hline \multicolumn{3}{|c|}{ Deskripsi } & Tenaga & Produksi \\
\hline \multirow{6}{*}{ Spearman's rho } & \multirow{3}{*}{ Tenaga } & Correlation Coefficient & 1.000 & $.917^{* *}$ \\
\hline & & Sig. (2-tailed) & & .000 \\
\hline & & $\mathrm{N}$ & 30 & 30 \\
\hline & \multirow{3}{*}{ Prod } & Correlation Coefficient & $.917^{* \star}$ & 1.000 \\
\hline & & Sig. (2-tailed) & .000 & \\
\hline & & $\mathrm{N}$ & 30 & 30 \\
\hline
\end{tabular}

Hasil menunjukan bahwa terdapat hubungan variable peran tenaga kerja dengan peningkatan produksi bawang merah dengan nilai $0,000<$ dari 0,05 didefiniskan terdapat hubungan yang signifikan (berarti) antara peran tenaga kerja terhadap peningkatan produksi bawang merah.Selanjutnya keeratan hubungan variabel peran tenaga kerja dengan peningkatan produksi bawang merah koefisien sebesar $0,917^{* *}$ memiliki arti sangat kuat (Tabel 4).

Produksi menjadi bagian akhir dari proses ekonomi yaitu dengan pemanfaatkan masukan atau input. Input produksi meliputi tenaga kerja, kuantitas, kualitas, ketepatan waktu, lahan, modal, serta tenaga Kerja. Ketersedian lahan adalah satu faktor penentu dalam produksi bawang merah, hal ini disebabkan luas lahan akan memiliki dampak terhadap jumlah produksi yang akan dihasilkan (Rijal dkk., 2016; Rosyadi dkk., 2017). Menurut pendapat Suratiyah, (2008) menjelaskan bahwa tanah pada suatu lahan memiliki fungsi dan peran dalan suatu produksi tanaman hal ini meliputi beberapa factor penting yaiti letak suatu lahan, intensifikasi, dan tingkat kesuburan tanah. Modal menjadi inti dalam 
industri bawang merah. Ketrsidiaan dan pemakaian modal ditujukan untuk menunjang output serta efisiensi nilai kerja (Minarsih dan Waluyati, 2019; Rijal dkk., 2016). Ketersediaan modal akan memberikan stimulus kepada petani untuk kegiatan produksi bawang merah berbanding lurus dengan hasil produksi, semakin banyak modal maka akan semakin tinggi juga produksi bawang merah. Penelitian Tungga Dangin dan Marhaeni, (2019) menjelaskan bawa modal yang didapatkan oleh suatu kelompok akan berbanding lurus dengan peningkatan produksi. Faktor produksi bawang juga dipegaruhi oleh tenaga kerja (Minarsih dan Waluyati, 2019). Kuantitas tenaga kerja yang tersedia dilapangan akan meningkatkan nilai produksi bawang merah. Ketersediaan tenaga kerja produksi bawang merah sangat penting dalam produksi. Selain kuantitas pekerja juga mempertimbangkan kualirtas tenaga kerja karena akan memiliki dampak etrhadap kualitas hasil produksi (Soekartawi, 2003).

\section{KESIMPULAN}

Kesimpulan penelitian menjukan ditemukan hubungan peran tenaga kerja terhadap peningkatan produksi bawang merah. Setiap variabel peranan tenaga kerja ditemukan nilai postif terhadap variabel peningkatan produksi bawang merah.

\section{REFERENSI}

Devi, S. R. M., \& Hartono, G. (2016). Faktor-Faktor Yang Mempengaruhi Keputusan Konsumen Dalam Membeli Sayuran Organik. Agric, 27(1), 60. https://doi.org/10.24246/agric.2015.v27.i1.p60-67

Guo, G., Wen, Q., \& Zhu, J. (2015). The Impact of Aging Agricultural Labor Population on Farmland Output: From the Perspective of Farmer Preferences. Mathematical Problems in Engineering, 2015, 1-7. https://doi.org/10.1155/2015/730618

Hauke, J., \& Kossowski, T. (2011). Comparison of Values of Pearson's and Spearman's Correlation Coefficients on the Same Sets of Data. Quaestiones Geographicae, 30(2), 87-93. https://doi.org/10.2478/v10117-011-0021-1

Minarsih, I., \& Waluyati, L. R. (2019). Efisiensi Produksi pada Usahatani Bawang Merah di Kabupaten Madiun. Jurnal Ekonomi Pertanian dan Agribisnis, 3(1), 128-137. https://doi.org/10.21776/ub.jepa.2019.003.01.13

Palacios-Lopez, A., Christiaensen, L., \& Kilic, T. (2017). How much of the Labor in African agriculture is provided by women? Agriculture in Africa - Telling Myths from Facts, 67, 52-63. https://doi.org/10.1016/j.foodpol.2016.09.017

Pawlak, K., \& Kołodziejczak, M. (2020). The Role of Agriculture in Ensuring Food Security in Developing Countries: Considerations in the Context of the Problem of Sustainable Food Production. Sustainability, 12(13), 5488. https://doi.org/10.3390/su12135488

Persaud Ajax, \& Schillo Sandra R. (2017). Purchasing organic products: Role of social context and consumer innovativeness. Marketing Intelligence \& Planning, 35(1), 130-146. https://doi.org/10.1108/MIP-01-2016-0011

Rahim, \& Diah. (2008). Ekonometrika pertanian (Pengantar, Teori dan Kasus). Penebar Swadaya.

Rijal, M., Jakfar, F., \& Widyawati, W. (2016). Analisis Faktor-Faktor Yang Mempengaruhi Produksi Usahatani Bawang Merah Di Desa Lam Manyang Kecamatan Peukan Bada. Jurnal IImiah Mahasiswa Pertanian, 1(1), 488-497. https://doi.org/10.17969/jimfp.v1i1.1321

Rosyadi, I., Achmad, N., \& Triyono, T. (2017). Meningkatkan Efisiensi dan Profitabilitas pada Usaha Tani Bawang Merah di Kabupaten Brebes. Warta LPM, 13(1), 65-76. https://doi.org/10.23917/warta.v13i1.3211

Seegebarth Barbara, Behrens Stefan Henrik, Klarmann Christiane, Hennigs Nadine, \& Scribner Lisa Luebbehusen. (2016). Customer value perception of organic food: Cultural differences and cross-national segments. British Food Journal, 118(2), 396-411. https://doi.org/10.1108/BFJ07-2015-0235

Soekartawi. (2003). Teori Ekonomi Produksi. PT Raja Grafindo Persada.

Sugiyono. (2012). Metode Penelitian Kuantitatif, Kualitatif, dan Kombinasi (Mixed Methods). Alfabeta.

Sugiyono. (2013). Metode Penelitian Pendidikan: Pendekatan Kuantitatif, Kualitatif, dan $R$ \& D. Alfabeta.

Suratiyah. (2008). IImu Usahatani. PT Penebar Swadaya. 
Tungga Dangin, I. G. A. B., \& Marhaeni, A. A. I. N. (2019). Faktor-Faktor Produksi Yang Mempengaruhi Pendapatan Pengerajin Pada Industri Kerajinan Kulit Di Kabupaten Badung. E-Jurnal Ekonomi dan Bisnis https://doi.org/10.24843/EEB.2019.v08.i07.p02 